\title{
Organic Edunet - Call for a Worldwide Platform in Organic Agriculture
}

\author{
Radics L. ${ }^{1}$, Pusztai P. ${ }^{2}$, Csambalik L. ${ }^{3}$, Szalai Z. ${ }^{4}$, Tóbiás A. ${ }^{5}$
}

\section{N F O}

Received 16 Sept. 2010

Accepted 10 Dec. 2010

Available on-line 3 Apr. 2013

Responsible Editor: A. B.

Sideridis

\section{Keywords:}

Organic.Edunet, digital

education, e-learning, organic

agriculture, agroecology.

\begin{abstract}
$\underline{\text { A B S TRACT }}$
Organic.Edunet (ECP-2006-EDU-410012 Organic.Edunet) aims to facilitate access, usage and exploitation of digital educational content related to Organic Agriculture (OA) and Agroecology. It deploys a multilingual online federation and digital environment of learning repositories, populated with quality content from various content producers. Organic.Edunet focuses on achieving interoperability between the digital collections of $\mathrm{OA}$ and Agroecology content of various EU countries. In this way, digital content that can be used to educate European Youth about the benefits of OA and Agroecology, becomes easily accessible, usable and exploitable. As the end of the project approaching the system has been set up and located to content providers preserving the network system. All partners related to education have uploaded all of their learning objects. In order to ensure the sustainability of the portal all partners contribute to affiliated partners' organization. The project offers a digital and user defined portfolio for them even in regular learning systems or lifelong learning.
\end{abstract}

\section{Introduction}

Consumers demand for food quality and safety, as well as, society's demand for more sustainable development, provide new opportunities for the agricultural sector (Williams, 2002). Consumers' fears, triggered by food scares and technological developments such as genetic modification and food irradiation, have been translated into serious concern about food safety, increasing demands for quality assurance and more information about production methods (Hammitt, 1990). In addition, public awareness of the irreversible damage done to the environment by practices that lead to soil and water pollution, depletion of natural resources, and destruction of delicate ecosystems, has led to calls for a more responsible attitude towards our natural heritage (Grunert and Juhl, 1995).

\footnotetext{
${ }^{1}$ RADICS, László

Corvinus University of Budapest, Faculty of Horticultural Sciences, Department of Ecological and Sustainable Production Systems, Budapest H-1118, Villányi út 29-43

laszlo.radics@uni-corvinus.hu

${ }^{2}$ PUSZTAI, Péter

Corvinus University of Budapest, Faculty of Horticultural Sciences, Department of Ecological and Sustainable Production Systems, Budapest H-1118, Villányi út 29-43

peter.pusztai@uni-corvinus.hu

${ }^{3}$ CSAMBALIK, László

Corvinus University of Budapest, Faculty of Horticultural Sciences, Department of Ecological and Sustainable Production Systems, Budapest H-1118, Villányi út 29-43

laszlo.csambalik@uni-corvinus.hu

${ }^{4}$ SZALAI, Zita

Corvinus University of Budapest, Faculty of Horticultural Sciences, Department of Ecological and Sustainable Production Systems, Budapest H-1118, Villányi út 29-43

magdolnazita.szalai@uni-corvinus.hu

${ }^{5}$ TÓBIÁS, Andrea

Corvinus University of Budapest, Faculty of Horticultural Sciences, Department of Ecological and Sustainable Production Systems, Budapest H-1118, Villányi út 29-43

andrea.tobias@uni-corvinus.hu
}

Radics L. , Pusztai P. , Csambalik L. , Szalai Z. , Tóbiás A.: Organic Edunet - Call for a Worldwide Platform in Organic Agriculture 
Against this background, Organic Agriculture (OA) has come to the fore as an agricultural approach that can not only produce safer agricultural products but it is environmentally sound too (Stolze et al., 2000).

In this light, the European Action Plan for Organic Food and Farming (2004) has identified the need for actions supporting the training and education of all stakeholders related to OA, covering aspects related to production, processing and marketing of OA products and their benefits, plus targeting OA products as the preferred option for both producers and consumers (Schmid et al., 2008).

Efficiency of organic farming can either grow or decrease over time depending on the nature of the technology and the learning process (Sipiläinen and Lansink, 2005). The European Commission and social partner organisations at EU level encourage the lifelong development of qualifications and competence. This is reflected in many policy reports and reviews (Field, 2000).

The main objectives of the Organic.Edunet project are the following ones:

- To support stakeholders producing content about Organic Agriculture (OA) and Agroecology to publish it in an online federation of learning repositories, described according to multilingual, standard-complying metadata.

- To deploy a multilingual online environment (the Organic.Edunet Web portal) that facilitates endusers' search, retrieval, access and use of the content in the learning repositories.

- To study educational scenarios that are able to introduce the use of the Organic.Edunet Web portal and the content in the repositories, in order to support teaching of the relevant topics, in highschools and agricultural universities.

- To evaluate project results in the context of both focused pilot trials and open validation events which permanently take place in various European schools and universities.

- To create organisational structures that reinforce the cooperation of stakeholders in this particular content area and support the sustainability of project results (Radics et al., 2008a, b).

The resources that are developed to support learning activities must be easily located, retrieved and be well selected to meet the needs of those persons to whom they are delivered (Tzikopoulos et al., 2005). That is why repositories (systems for the storage, location and retrieval of content) are so essential to the further integration of information technologies and learning (Holden, 2003). Digital repositories, in the broadest sense, are used to store any digital material. However digital repositories for learning resources are considerably more complex both in terms of what needs to be stored and how it may be delivered (Duncan, 2002). The definition of a digital learning repository (DLR) is the following: a digital repository is a DLR if it is created in order to provide access to digital educational materials and if the nature of its content or metadata reflects an interest in those materials being used in an educational context (Holden, 2003).

One type of DLRs is that store learning objects, which are called learning object repositories. A LO (Learning Object) is defined as: "an independent and self-standing unit of learning content that is predisposed to reuse in multiple instructional contexts" (Polsani, 2003).

\section{Materials and methods}

It is always a key point to determine the most applicable method to store the digital LOs (Learning Objects) for further use or search. The SCAM (Standardized Content Archive Management) is a web based content archive concept which gives you the possibility to use metadata and make the resources structured and well defined.

Confolio, which is a SCAM learning object repository, aims to provide a structured background depot for the uploaded LOs. This system is a user structured electronic portfolio to store and make accessible the content. Confolio is used in this project as a front-end web application and acts as a first link between the users and the back-end. The back-end of this project is a user related activity.

Main tool for it is the Organic.Edunet Portal, using the structured contents and make it searchable. User may just simple use the back-end to get information on his own or may organise complete 
education courses upon it. To fulfil this requirement all the contents must be collected in an applicable format.

Organic.Edunet project consortium consisting of sixteen member organizations can be categorized into three typical parties, which have different functions and responsibilities:

- Technical partners dealing with the technical implementation, development and maintenance of the IT background, e.g. web interface, search engine, network connection of remote repositories, etc.

- Educational institutions as content providers. Universities and secondary schools upload their electronic educational materials to the system and support the integration of novel pedagogical methodology to the present curriculum. Corvinus University of Budapest, Hungary is a good example for this responsibility sharing its university level educational materials and learning objects optimized for distance and e-learning courses.

- Organizations related to organic agriculture and agroecology. These parties can contribute as content providers as well and support dissemination activities through their wide client database. Association for Hungarian Organic Farming (MÖGÉRT) supports the project by both functions mentioned.

\section{Results}

First phase of building Organic.Edunet was to set up the criteria for collecting the LOs. It was quite important to clearly declare the level of possible contents as well. The expected over 5000 contents all belong to organic agriculture and agroecology both scientific and information level.

The Organic.Edunet Repository is being uploaded continuously, however, greater amount of the materials are still uploaded, annotated with metadata and validated, and has reached the targeted number before the end of the project. This huge repository can not be used without clearly defined ontology in the background. One of the main results is the ontology, which is the biggest milestone of the first halt in of the project's life. The categories are set up to cover all the possible content fields in both organic agriculture and agroecology and continuously revised and extended according to professional and test feedback.

\subsection{Confolio Home Page - http://oe.confolio.org}

Confolio is the system which enables for educational bodies to upload and edit their own learning materials and share them with other interested parties. In the phase of project work only official project partners could use Confolio. However, the choice is up to every external content provider to become an affiliated partner and make use of Confolio. In order to starting use Confolio as an Organic.Edunet Repository first of all one has to create a user name and a password, which has to be written in the Login window (Figure 1).

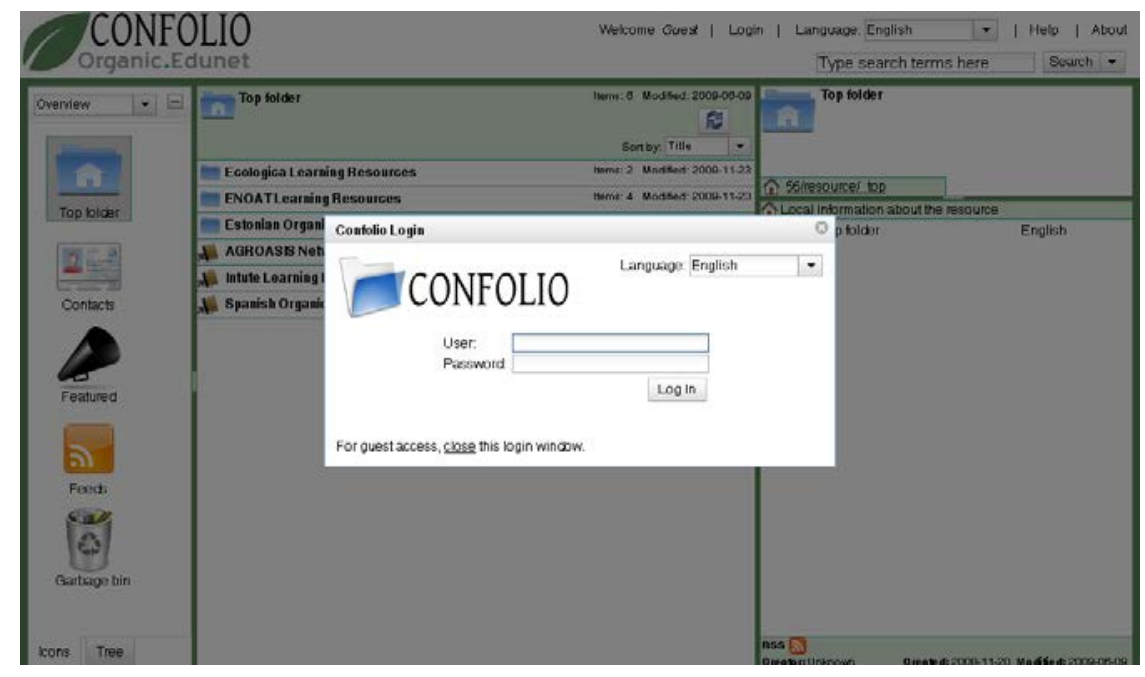

Figure 1. Confolio Login window 


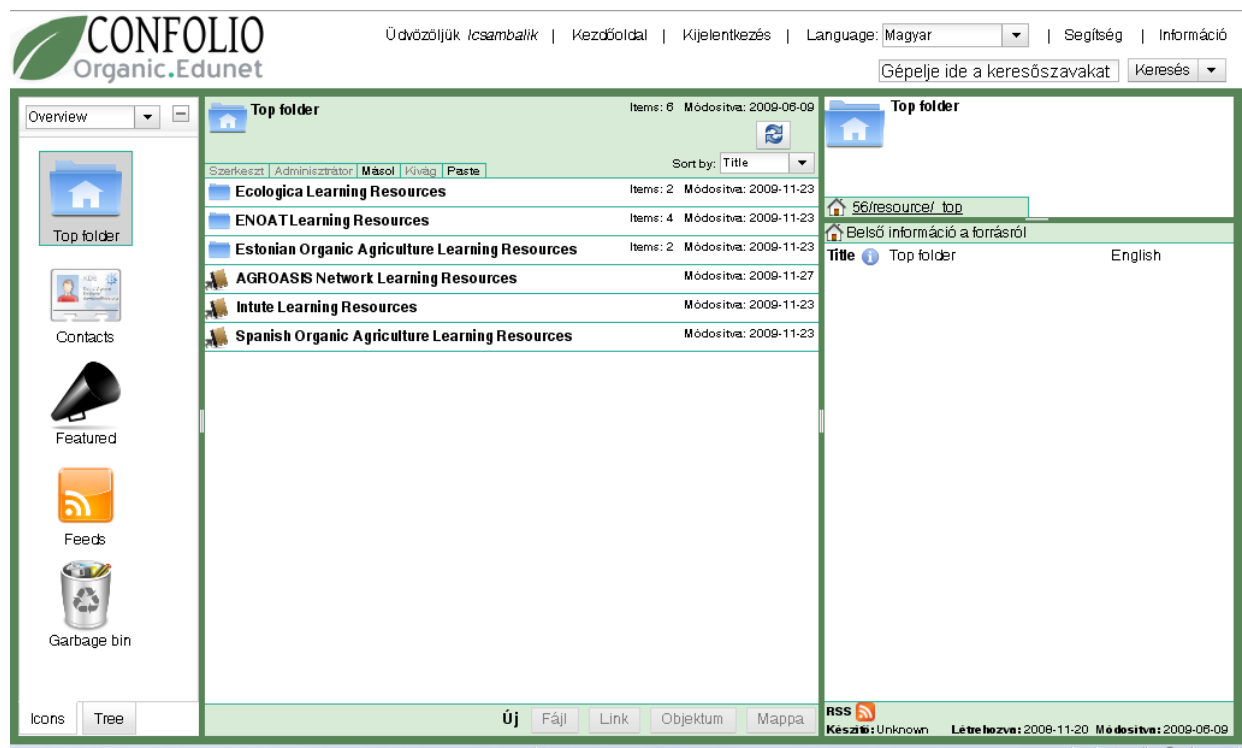

Figure 2. Confolio Top folder

After login, the user is directed to the Top folder (Figure 2). Guest users are allowed to use Confolio as web based file manager to check uploaded contents but not allowed to upload own content or edit any of other's.

\section{- Uploading a resource}

After successful login, the registered user can upload a resource clicking on File button (Figure 3).

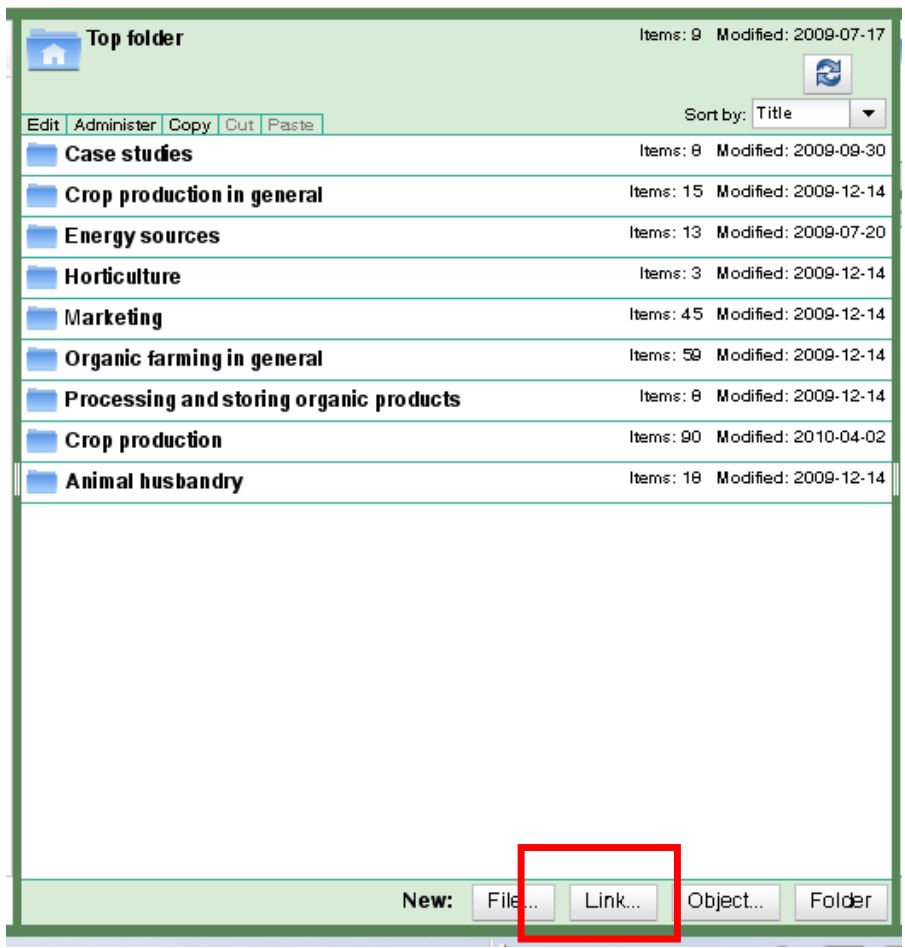

Figure 3. First step of uploading files to Confolio

The whole file system is built up on partner institutions' folders as seen on Figure 2. You may open your own folder and upload new content or edit previously uploaded ones.

Source of uploading can be chosen easily by 'Browse' button (Figure 4). Format and type of the desired file can be selected from a drop-down list. Title and description of the file should be given in separate boxes. Finally one should choose reading and writing access rights, what could be private, 
user or public. After accepting that the resource has been pre-checked according to the rules of the Organic.Edunet the button "Next" can be pushed.

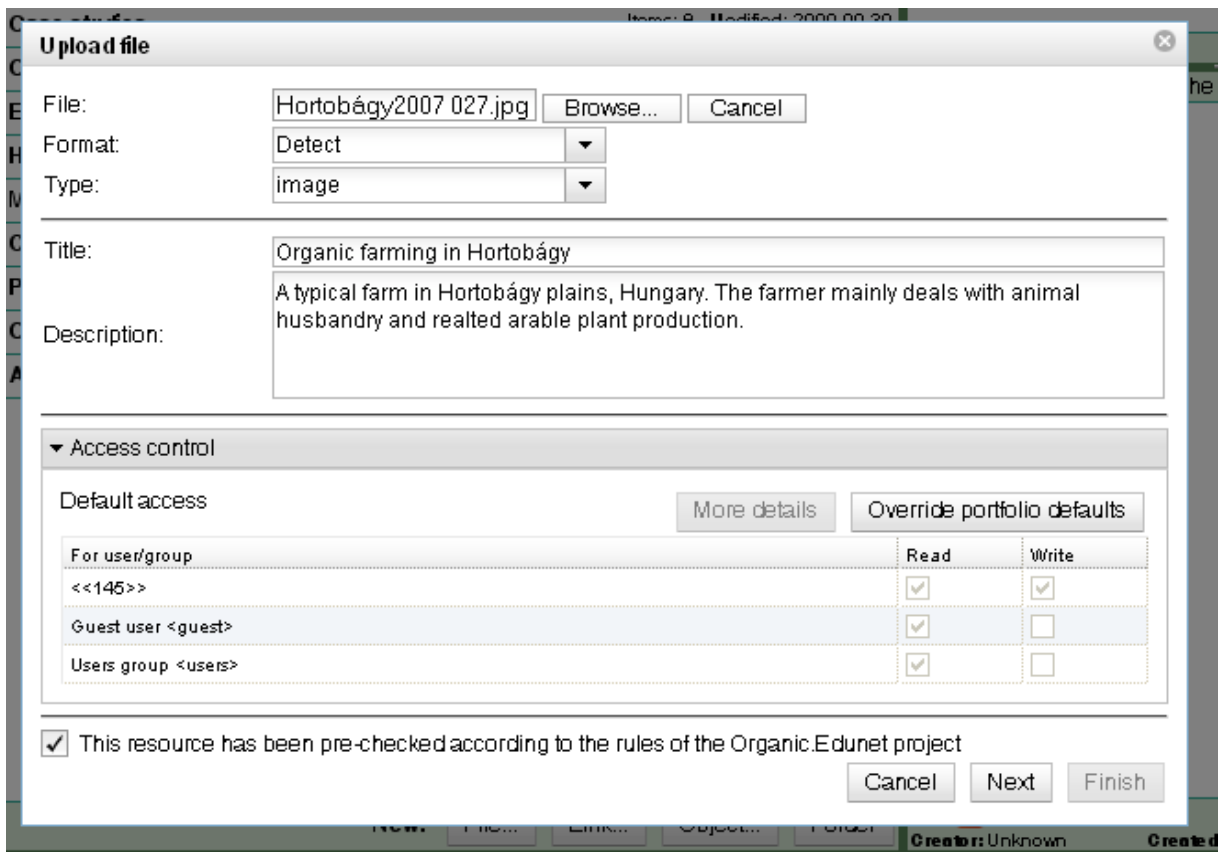

Figure 4. Second step of uploading files to Confolio

In order to make all uploaded Learning Objects (LO) valuable for all partners and interested users English has been determined as a common language, therefore all essential information related to a LO has to be provided in English and native language, even though the $\mathrm{LO}$ - e.g. a text file - is in native language. After completing the required data in both languages (Figure 5), the LO will be uploaded to Confolio. If any of the data is missing, a warning message appears and blocks uploading, until the required field is filled out.

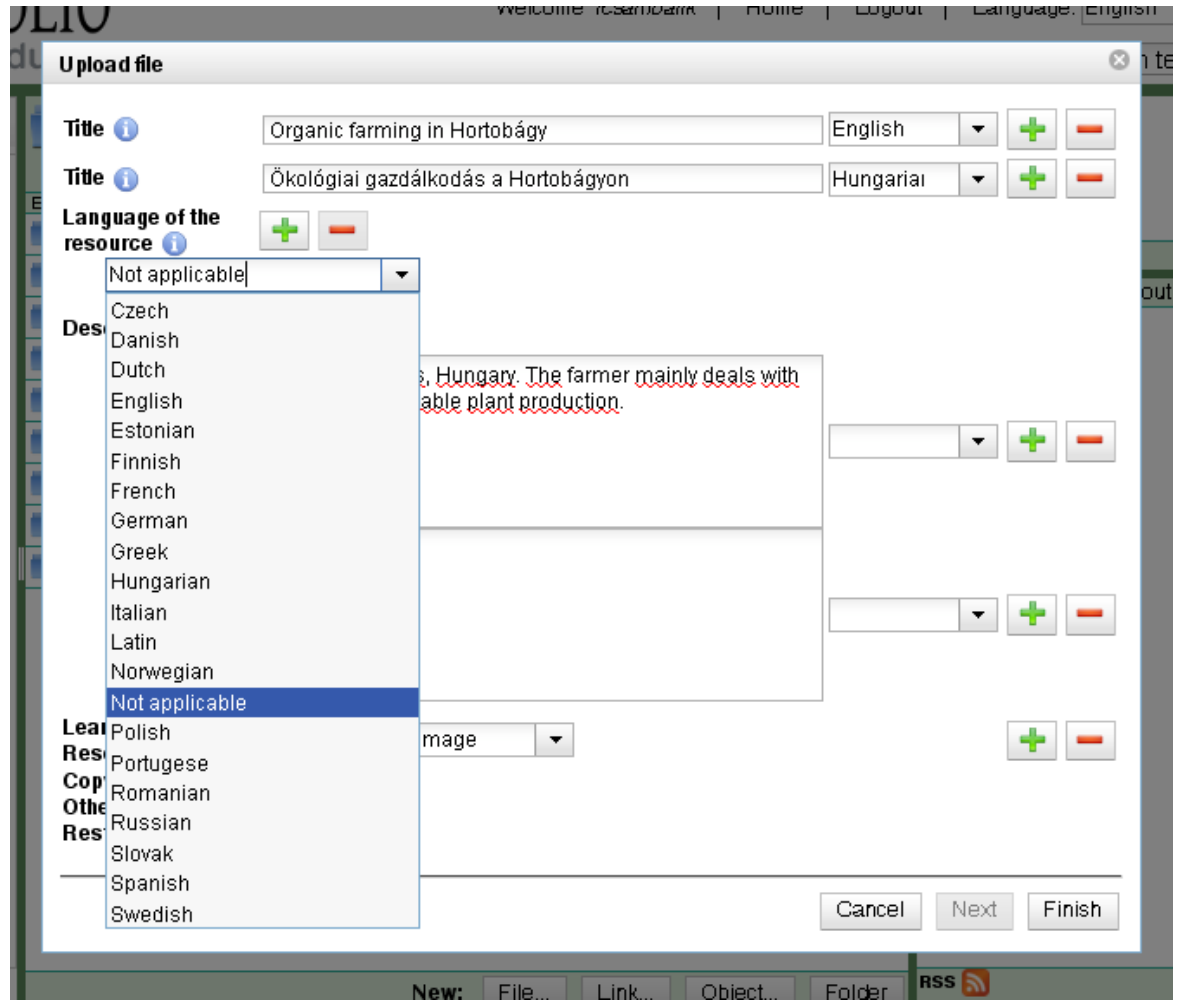

Figure 5. Providing essential metadata both in English and native language 
The web application Confolio is just the container to store the data but it was necessary to make exact description in Confolio about the contents. The metadata system must be based on ontology and other parameters that enhance the utilization of a LO. Metadata are divided into three levels as mandatory, recommended and optional fields. Mandatory data are title, language, a short description and information of cost and copyright status of the content. Mandatory metadata are enough to describe the content clearly and make it available for search. Any recommended or optional fields are filled in will provide better search in the database (Figure 6).

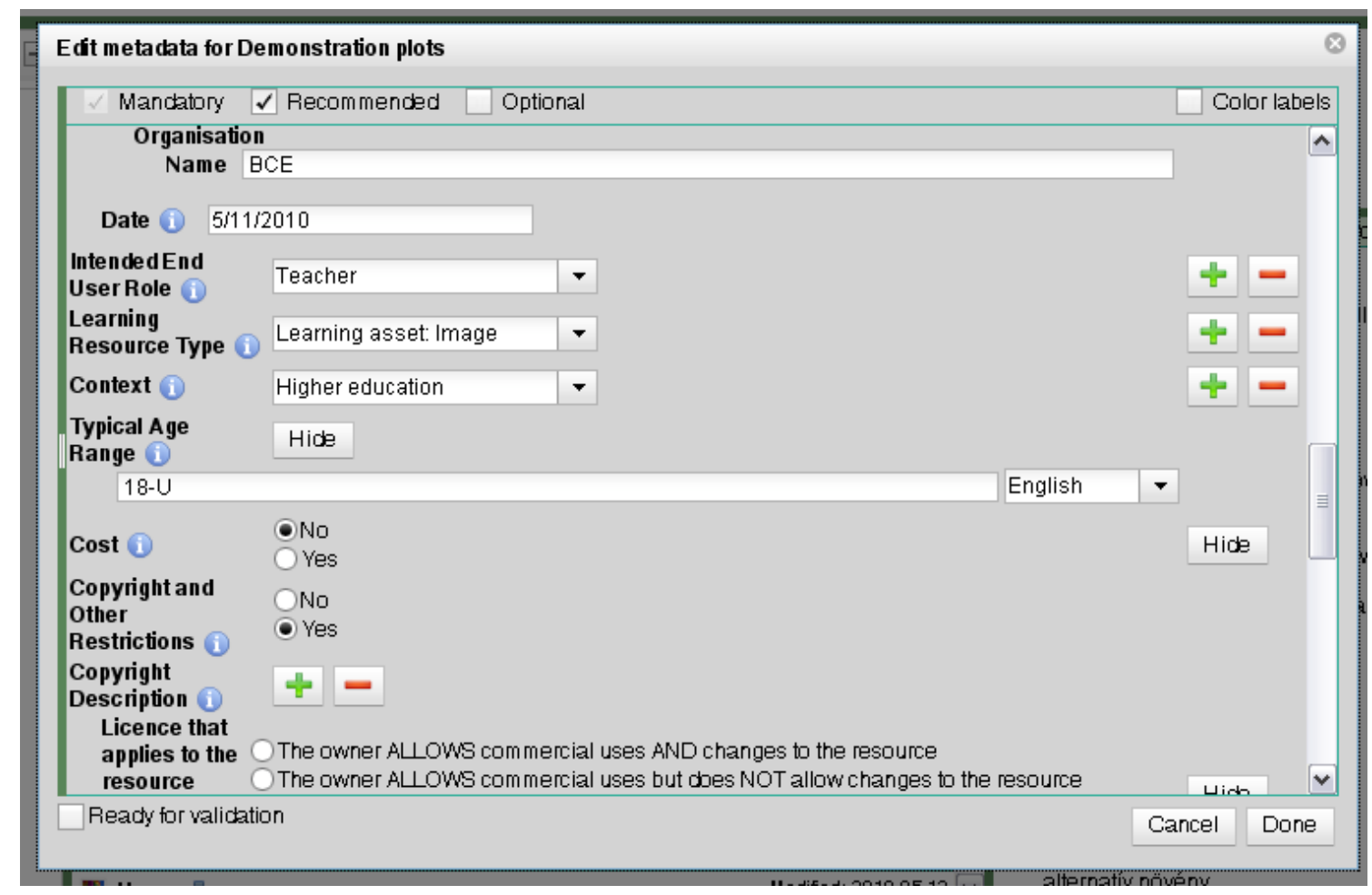

Figure 6. Metadata edition of a Learning Object

Each partner is asked to fill in as much recommended and optional metadata, because it will help the end users to find their contents and gives the possibility for advanced search.

The digital resources are usually typical learning objects and sometimes are references or links. Collected files are mainly documents (doc and pdf), image files (jpg, png), and video files (mpg, wmv, avi). Other resources are related to digital books, concepts, contacts, events and web-links. All the resources are described with detailed metadata.

It is important to provide multimedia content, like pictures, movies, sound files to fulfil the requirements of an e-learner or distant learner. Uploaded documents are mainly handbooks, tutorials, relevant publications and aim to give deep information a specific subject of organic agriculture or agroecology. It is important also to give presentations for the better understanding and provide mixed information of images and text explanations. It is also useful and necessary to give references or links to web sites, external resources to offer background or additional information or just make your content better supported.

Typical content sources are the contents of Organic.Edunet Consortium members, ECOLOGICA Project Resources, FAO Capacity Building Portal, AGROASIS Project Resources, ENOAT Learning Resources, Estonian and Spanish Organic Agriculture Learning Resources and INTUTE Learning Resources.

After uploading and editing metadata of the given source, user gets the screen of Figure 7. 


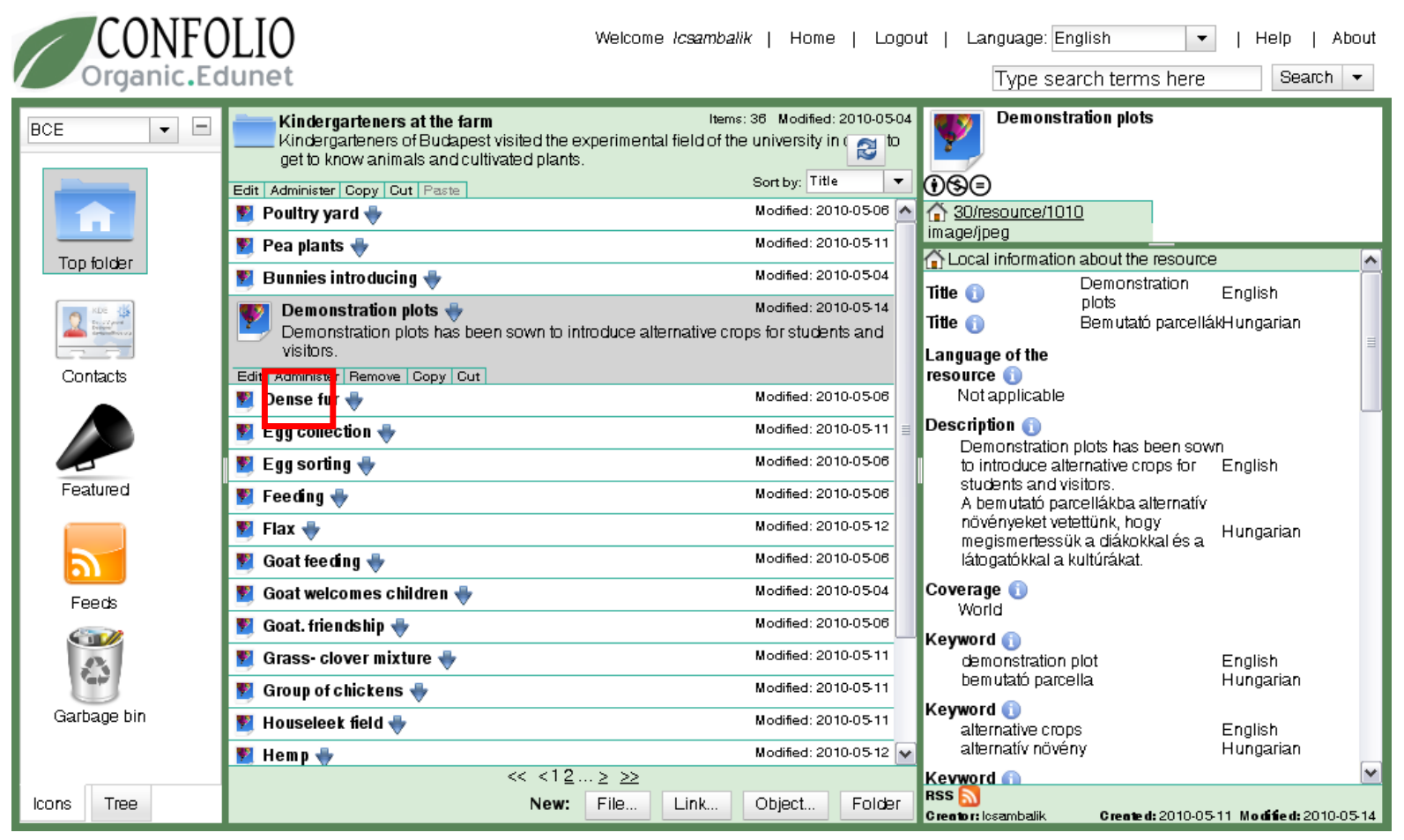

Figure 7. Users’ Confolio

You can edit the metadata inserted for any resource if you are registered member in the user's Confolio by clicking on 'Edit' in the drop-down list beside the resource (marked with red) when the same surface appears like on Figure 6.

\section{- Searching for a Learning Object}

Searching of LOs is important for end-users of the system, e.g. pupils, students, teachers and lecturers. The Front-end page of Confolio can be found at http://portal.organic-edunet.eu/index.php . As the portal is designed user-friendly, proper use of it can be explored individually.

Users have three options for searching: Text based search, Semantic search and Tag based search, as well as free browsing and tag cloud can be found at the main page of the Organic.Edunet portal.

Text-Based Search works in a typical text-based searching way. It looks for the keywords that the user is typing, into the title and description of all the educational resources in the federation. To facilitate limiting down the results, the Text-Based Search interface also allows users to filter the returned results according to their Learning Resource Type or their targeted Educational Level.

Semantic Navigation allows users to search for resources according to an ontology of Organic Agriculture concepts, providing results that are related to the particular concepts in the ontology. Users can directly ask for resources that are related to a particular concept in the ontology. For a more elaborated search, users may define a number of interest points upon the ontology, and ask for resources that are related to them.

Tag-Based Search allows users to search for resources according to the way other users have annotated (e.g. tagged or rated) them in the past. Users can either search for resources that have been tagged with a particular word (using a 2-D or 3-D interface), or can see which resources are most popular to other users (i.e. the ones that have been rated highly). For registered users only: when logged-in, registered users have access to more advanced search functionalities related to social navigation, such as receiving recommendations about interesting resources that match their profile.

\section{- Educational Scenarios}

Organic.Edunet team described the main points of possible end user situations mainly in education. Two groups of partner institutions developed several education scenarios where Organic.Edunet may 
be integrated or used as only resource for secondary schools and universities. Test courses have been organized to test the scenarios and feedback from pupils, students and teachers has been incorporated into the system.

The philosophy of using Organic.Edunet in direct education based on the concept of involving students into learning material gathering and processing. After a special collection work of a tutor, main resources are listed to students and they are free to download and use them in their own work. This system is fitted to regular secondary or university lecture structure but gives wider interactivity to both parties.

The concept of using Organic.Edunet in distant learning systems gives just access to the repository and students will search and use the content independently. It means less tutor activity and better fit to e-learning situation.

Here are two demonstrative cases to describe the basic situations:

- A teacher uploads digital resources on Confolio making them widely available

- Another teacher searches for digital resources to support teaching activities on Organic Agriculture

\section{First Scenario}

- You teach a particular topic for some time (e.g. Organic Agriculture)

- You want to share the material you have created

- You describe and upload them in Confolio providing all the necessary data

- The resources are accessible to anyone through Organic.Edunet Web Portal

\section{Second Scenario}

- A teacher gives a lecture on Organic Agriculture in high school

- Searches for online material to support it (i.e. lesson plans, document, videos)

- Visits the Organic.Edunet Web Portal

- Retrieves the resource uploaded in the Confolio tool

Added Value

- Easier retrieval of resources

- As they are described in standardized way

- Refine search with specialized terms

- Learning time, intended audience, difficulty, age range

Scenarios are organized around a learning target e.g. to introduce pupils the advantages of organic farming in household gardening. For this aim, theoretical and practical activities can be compiled, pupils can have a small area in the school garden, where they can produce vegetables from sowing until harvesting and cooking of the yield.

In university level a lecturer could possibly popularize the use of renewable energy sources in agriculture. Therefore the lecturer invite experts of the topic, who can answer the questions of the students, or an excursion can be organized, when such farms visited, where professional utilization of renewable energy sources can be observed. Practical experiences should always be supported be theoretical knowledge, which is accessible through Organic.Edunet portal. Projects done by students can be shared at the portal, which can be useful for lecturers who would like to compile such scenarios.

\section{Conclusion}

The project studies educational scenarios that introduce the use of the Organic.Edunet portal and content to support teaching of topics related to OA and Agroecology in two cases of formal educational systems, i.e., high-schools and agricultural universities (Figure. 8). 


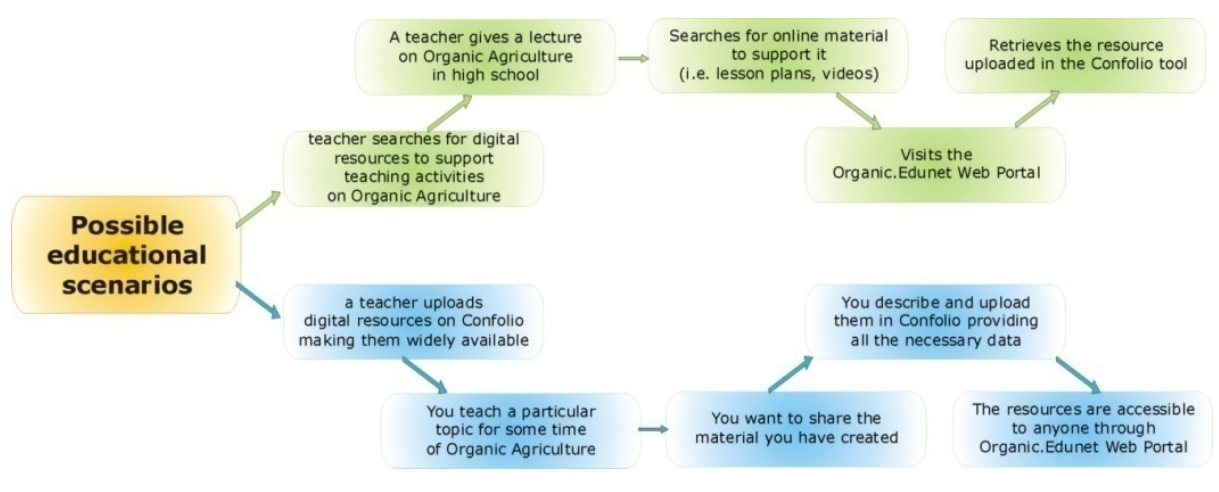

Figure 8. The two possible educational scenarios

Wide range of possibilities provides new ways to users in building up own scenarios based on Organic.Edunet portal. Moreover, multilingual online environment of Organic.Edunet portal makes it tractable and available world-wide. This gives a good possibility for all countries to join as affiliated partner or as user of free education materials.

One of the most human characteristic of OA is versatility. This could be well served with other partners who hold possession of knowledge about OA of certain continents. It would be very helpful not only for other European users but for students and professionals of other continents, too. E.g. more and more pests and weed species are spreading from south to north, and Organic.Edunet could be a platform where researchers or organic farmers can find answers or ideas how to fight against these pests. Besides, European education materials of organic farming could mean a good basis where educationalists and students can find starting point or help for their work. Organic.Edunet aims to become an international platform supporting knowledge flow in the topic of OA and Agroecology.

\section{Acknowledgements}

The mentioned project is funded by the European Commission under the name of "Organic.Edunet: A Multilingual Federation of Learning Repositories with Quality Content for the Awareness and Education of European Youth about Organic Agriculture and Agroecology" Targeted Project of the eContentplus programme (ECP-2006-EDU-410012 Organic.Edunet).

\section{References}

Duncan C. 2002. Digital repositories: the ‘back-office of e-Learning or all e-Learning?’In Proc. ALT-C 2002.

Field J. 2000. Governing the ungovernable. Why lifelong learning policies promise so much yet deliver so sittle. Educational Management Administration and Leadership 28(3), 249-261.

Grunert S. C. and H.J JUHL. 1995. Values, environmental attitudes, and buying of organic foods. Journal of Economic Psychology 16(1), 39-62.

Hammitt J. K. 1990. Risk perceptions and food choice: an exploratory analysis of organic- versus conventionalproduce buyers. Risk Analysis 10(3), 367-374.

Holden, C. 2003. From local challenges to a global community: learning repositories and the global learning repositories summit. Version 1.0, Academic ADL Co-Lab, November 11.

Polsani P. 2003. Use and abuse of reusable learning objects. Journal of Digital Information 3(4). Retrieved July 25, 2005, from http://jodi.ecs.soton.ac.uk.

Radics L., S. Basile, Z. Szalai, P. Pusztai, and L Radics Jr. 2008a. From the COMPASS project to ECOLOGICA and to the Organic Edunet. In Proc. 4th International Conference on Information and Communication Technologies in Bio and Earth Sciences (HAICTA 2008).

Radics L., P. Pusztai, N. Manouselis, and X. Tsilibaris. 2008b. Organic.Edunet for Organic Agriculture and Agroecology. 16th IFOAM Organic World Congress. 
Schmid O., S. Dabbert, C. Eichert, V. Gonzalvez, N. Lampkin, J. Michelsen, A. Slabe, R. Stokkers, M. Stolze, C. Stopes, P. Wollmuthova, D. Vairo, and R. Zanoli. 2008. Organic Action Plans. Development, implementation and evaluation. pp. 114.

Sipilainen T., and O. Lansink. 2005. Learning in Organic Farming - an application on Finnish dairy farms. In Proc. XIth Congress of the EAAE (European Association of Agricultural Economists), Copenhagen, Denmark, August 24-27, 2005

Stolze M., A. Piorr, A. Haring, and S. Dabbert. 2000. Environmental impacts of organic farming in Europe. Organic Farming in Europe: Economics and Policy 6. Universität Hohenheim, Stuttgart-Hohenheim.

Tzikopoulos A., N. Manouselis, C. Costopoulou, C. Yalouris, and A. B. Sideridis. 2005. Investigating digital learning repositories' coverage of agriculture-related topics. In Proc. International Congress on Information Technologies in Agriculture, Food and Environment (ITAFE05), Adana, Turkey October 12-14, 2005.

Williams C. M. 2002. Nutritional quality of organic food: shades of grey or shades of green? In Proc. Nutrition Society 61, pp. 19-24. 